\title{
Prevalence and risk factors for cervical squamous intraepithelial lesions among women infected with HIV-I in Makurdi, Nigeria
}

This article was published in the following Dove Press journal:

International Journal of Women's Health

13 February 2012

Number of times this article has been viewed

\author{
Terrumun Z Swende ${ }^{1,2}$ \\ Stephen D Ngwan ${ }^{2}$ \\ Laadi T Swende ${ }^{3}$ \\ 'Department of Obstetrics \\ and Gynecology, College of Health \\ Sciences, Benue State University, \\ Makurdi, ${ }^{2}$ Department of Obstetrics \\ and Gynecology, ${ }^{3}$ Department of \\ Family Medicine, Federal Medical \\ Center Makurdi, Makurdi, Nigeria
}

Correspondence: Terrumun Z Swende PO Box 973, Makurdi 97000I, Benue State, Nigeria

Tel +2348065720059

Email swendetz@yahoo.com
Background: The purpose of this study was to determine the prevalence and risk factors for cervical squamous intraepithelial lesions (SIL) among women infected with human immunodeficiency virus type 1 (HIV-1) receiving care at the Federal Medical Center Makurdi, Nigeria.

Methods: Between March and December 2009, a total of 253 women infected with HIV-1 had cervical smears taken for cytology. HIV-1 RNA viral load and CD4 counts were also measured.

Results: Of the 253 women, cervical SIL were present in 45 (17.8\%). However, abnormal cervical cytology was noted in $146(57.7 \%)$. Of those with abnormal cervical cytology, $101(39.9 \%)$ women had atypical squamous cells of undetermined significance, $16(6.3 \%)$ had low-grade SIL, and 29 (11.5\%) women had high-grade SIL. The median CD4 lymphocyte count was lower in participants with cervical SIL compared with those without (132 versus 184 cells $\left./ \mathrm{mm}^{3} ; P=0.03\right)$. The median HIV-1 RNA viral load was higher in women with cervical SIL $(102,705$ versus 64,391 copies $/ \mathrm{mL} ; P=0.02)$. A CD4 lymphocyte count of $<200$ cells $/ \mathrm{mm}^{3}$ and an HIV-1 RNA viral load of $<10,000$ copies $/ \mathrm{mL}$ were found to be significantly associated with cervical SIL.

Conclusion: A high prevalence of cervical SIL was found among HIV-1-infected women in Makurdi, Nigeria. Increased immune suppression and HIV-1 viremia are significantly associated with cervical SIL.

Keywords: cervical squamous intraepithelial lesions, human immunodeficiency virus, risk factors, immunosuppression, cervical dysplasia, Nigeria

\section{Introduction}

Cancer of the uterine cervix is the second most common cancer among women worldwide, with an estimated 493,000 new cases in $2002^{1,2}$ and over 250,000 deaths in $2005 .^{3}$ Without urgent action, deaths from cervical cancer are projected to rise by almost $25 \%$ over the next ten years. ${ }^{3}$ Therefore, cervical cancer presents a serious global problem. ${ }^{2}$ Over $80 \%$ of cases of cervical cancer occur in developing countries where it represents the commonest malignancy affecting women. ${ }^{4,5}$ In Nigeria, it is the commonest cancer of the female genital tract. ${ }^{6}$ Most women who die from cervical cancer, particularly in developing countries, are in the prime of their life. They may be raising children, caring for their family, and contributing to the social and economic life of their town or village. Their death is both a personal tragedy and a sad and unnecessary loss to their family and their community. ${ }^{3}$ 
Invasive cancer of the cervix is considered to be a preventable condition, given that it is associated with a long preinvasive stage, making it amenable to screening and treatment as long as it is detected early and managed effectively. ${ }^{3,7}$ Cancer of the cervix has been classified as an acquired immune deficiency syndrome (AIDS) defining cancer by the US Centers for Disease Control and Prevention. ${ }^{8}$ Unfortunately, the global human immunodeficiency virus (HIV) epidemic continues to expand, with about five million people becoming infected each year and an estimated 39.5 million people living with HIV at the end of 2006. ${ }^{9}, 10$ With an estimated 2.95 million people living with HIV in Nigeria in 2008, Nigeria ranks as one of the countries with the highest burden of HIV infection in the world, next only to India and South Africa. ${ }^{11}$ Over the decades, the epidemic, once dominated by infected males, has become progressively feminized. In sub-Saharan Africa, where about two-thirds of the global disease burden occurs, $57 \%$ of adults living with HIV are women. ${ }^{12}$ As more women contract the virus, the risk of cervical squamous intraepithelial lesions (SIL) or cervical intraepithelial neoplasia and ultimately cervical cancer increases. ${ }^{13}$

Despite the fact that HIV infection and cervical cancer constitute a major reproductive health challenge in Nigeria and Africa, only a few studies have investigated the relationship between HIV infection and cervical SIL. Both CD4 lymphocyte count and HIV RNA viral load are independent predictors of the course of HIV/AIDS, and the frequency of occurrence and severity of cervical SIL in HIV-infected women increase as the CD4 count declines. ${ }^{14}$ However, the role of HIV RNA viral load and antiretroviral therapy regarding the risk of cervical SIL has not been satisfactorily established. This study aimed to determine the prevalence of cervical SIL among a cohort of women infected with HIV-1 and to identify its relationship with risk factors, CD4 cell count, and HIV-1 RNA levels in Makurdi, north central Nigeria.

\section{Materials and methods}

The Federal Medical Center Makurdi, is situated in Benue State, a low resource setting with the highest burden of HIV infection (seroprevalence 10.6\%) in the Nigerian federation. ${ }^{11}$ The HIV care clinic of the center, located on the banks of the River Benue, is a regional reference center for comprehensive treatment and support of people living with HIV. This study was approved by the research ethics committee of the Federal Medical Center Makurdi in October 2008. After detailed explanation of the study and clinical procedures, all 253 participants provided their written consent in English and pretested translations of the local languages for illiterate women. Consecutive nonpregnant clients were recruited into the study between March and December 2009. Other eligibility criteria included documented evidence of HIV-1 infection by Western blot (Immunetics Inc, Boston, MA) and current absence of acute illness. Excluded from the study were clients who declined to participate, pregnant women (from menstrual history), women in the puerperium, women with obvious genital tract lesions and infection (referred for appropriate treatment), and those with a prior history of treatment for preinvasive and invasive cervical neoplasia.

Demographic data were collected using a pro forma, and included age, parity, marital status, number of lifetime sexual partners, history of tobacco smoking, and previous sexually transmitted infection. History of use of highly active antiretroviral therapy (HAART) was obtained and verified from client records. All study participants on HAART during the study period were on a regimen consisting of two nucleoside reverse transcriptase inhibitors (stavudine or zidovudine and lamivudine) and one non-nucleoside reverse transcriptase inhibitor (nevirapine or efavirenz). All patients on HAART were receiving first-line drugs according to national guidelines. None of the clients recruited were on second-line drugs.

The CD4 count was measured using flow cytometry (Cyflow; Partec, Germany) and reported as cells per cubic milliliter of blood (cells $/ \mathrm{mm}^{3}$ ). HIV-1 RNA viral load was determined by nucleic acid amplification (Roche-Ampliclor HIV-1 monitor test, version 1.5; Roche Molecular Systems Inc, Branchburg, NJ). Results were expressed as the number of RNA copies per milliliter of plasma (copies $/ \mathrm{mL}$ ). Values of 400 copies $/ \mathrm{mL}$ and below were regarded as undetectable. Blood samples for CD4 count and viral load were taken on the same day as the Papanicolaou smear.

All pelvic examinations were performed by a gynecologist or a trained gynecology resident. The clients were placed in the lithotomy position and a Cusco's speculum applied. Following visual inspection with a good light source, the cervix was assessed for gross lesions and abnormal discharge. Cervical smears were obtained using the Ayre's spatula from both the ectocervix and endocervix. Smears were made at two points on prelabelled glass slides and then fixed immediately in $95 \%(\mathrm{v} / \mathrm{v})$ alcohol in coupling jars. These were delivered to the cytopathology laboratory for staining and microscopic examination. All the slides were stained using the Papanicolaou staining technique. The fixed slides were stained in Harris hematoxylin. The smear was decolorized 
with acid alcohol and rinsed in Scott's tap water. They were then stained in orange $G$ stock solution and finally stained with Eosin Azure 50. The slides were further rinsed in two changes of $95 \%$ alcohol, cleared in xylene, and mounted in a neutral synthetic resin medium. To ensure unbiased reporting, the cytopathologist was blinded to the clinical profile of the samples. Cytology was reported using the Bethesda system of classification by an experienced cytologist/pathologist. The smears were reported as normal, inflammatory, atypical squamous cells of undetermined significance, low-grade SIL, or high-grade SIL. Women with initial "inflammatory" Papanicolaou smear results were treated appropriately and reconsidered afresh for recruitment into the study. With the exception of patients with a normal report, all others were referred to the gynecology clinic for further evaluation.

\section{Statistical analysis}

All data were entered and the analysis was performed using the Epi-info version 3.3.2 (CDC Atlanta, GA) computer software program. The $t$-test was used to compare differences in normally distributed continuous variables between subjects with and without cervical SIL. Non-normally distributed variables were compared using the Mann-Whitney test. Univariate analysis using the Chi-square $\left(\chi^{2}\right)$ statistic was performed to identify risk factors associated with cervical SIL. Multivariate logistic regression was used to identify independent risk factors for cervical SIL. Variables were entered into the model if their $P$ value on univariate analysis was 0.25 or less. $P<0.05$ was considered to be statistically significant.

\section{Results}

The mean age of the 253 participants was $34.2 \pm 6.4$ (range 20-60) years. The median number of lifetime sexual partners was five (range 0-60), and 107 (42.3\%) women had a prior history of sexually transmitted infection (Table 1). A total of 104 (41.1\%) participants in the study were on HAART, with a mean duration of use of $16 \pm 2$ (range 1-36) months. The predominant HAART regimen was lamivudine, stavudine, and nevirapine (67.3\%), while zidovudine, lamivudine, and nevirapine was the regimen used by $26 \%$ of the patients. Other regimens were being taken by $6.7 \%$ of the patients. The median CD4 count was 174 (range $12-1468$ ) cell $/ \mathrm{mm}^{3}$. HIV-1 RNA levels were detectable in 205 (81.0\%) women, with a median detectable level of 64,786 (range 426-1,854,296) copies/mL. There were $146(57.7 \%)$ women with abnormal cervical cytology. Of these, 101 (39.9\%) women had atypical squamous cells of undetermined significance. SIL was present in $45(17.8 \%)$ women. Among the women with SIL,
Table I Key sociodemographic characteristics and risk factors for squamous intraepithelial lesions in 253 women in Makurdi, Nigeria, infected with HIV-I ${ }^{a}$

\begin{tabular}{ll}
\hline Characteristic & Value \\
\hline Age (years) & $34.2( \pm 6.4)$ \\
Parity & $2( \pm 2)$ \\
Educational status & \\
$\quad$ None & $69(27.3)$ \\
Primary & $19(7.5)$ \\
Secondary & $107(42.3)$ \\
Tertiary & $58(22.9)$ \\
Married & $134(53.0)$ \\
Previous sexually transmitted infection & $107(42.3)$ \\
Tobacco smoking & $28(11.0)$ \\
Number of lifetime sexual partners & $5( \pm 4)$ \\
Use of HAART & $104(4 I .1)$ \\
CD4 count, cells/mm ${ }^{3}$ & \\
$\leq 200$ & $125(49.4)^{*}$ \\
$20 I-499$ & $105(4 I .5)$ \\
$\geq 500$ & $23(9.1)$ \\
HIV-I RNA, copies/mL & \\
$\geq 400$ & $205(8 I .0)$ \\
$\leq 400$ & $48(19.0)$ \\
Cervical cytology & \\
Normal & $107(42.2)$ \\
ASCUS & $10 I(39.9)$ \\
LSIL & $16(6.3)$ \\
HSIL & $29(I I .5)$ \\
\hline Note 2 a &
\end{tabular}

Notes: aValues are given as mean \pm standard deviation or number (percentage); *2I naive women were having CD4 estimation for the first time.

Abbreviations: ASCUS, atypical squamous cells of undetermined significance; HAART, highly active antiretroviral therapy; LSIL, low-grade squamous intraepithelial lesions; HSIL, high-grade squamous intraepithelial lesions; HIV-I, human immunodeficiency virus type $\mathrm{I}$.

low-grade SIL and high-grade SIL was present in $16(6.3 \%)$ and $29(11.5 \%)$ of cases, respectively. No case of invasive cervical cancer was identified.

The mean age of participants with SIL was $36 \pm 7$ years compared with $33 \pm 5$ years for women without SIL $(P=0.009$; Table 2). However, the parity of participants was similar in the two groups. Women with SIL did not have a greater number of lifetime sexual partners and had rates of history of sexually transmitted infections similar to that of the women without SIL. Likewise, tobacco smoking and mean duration on HAART were similar in women with and without SIL (Table 2). Women with SIL had a median CD4 cell count of 132 cells $/ \mathrm{mm}^{3}$ compared with 184 cells $/ \mathrm{mm}^{3}$ for those without SIL $(P=0.03)$. The HIV-1 RNA viral load was also significantly higher in women with SIL compared with that in women without SIL (102,705 versus 64,391 copies/mL, respectively; $P=0.002$, Table 2 ).

The results of the multivariate analyses are presented in Table 3. Having adjusted for other determinants, the risk 
Table 2 Demographic characteristics and selected risk factors for HIV-I infected women with and without squamous intraepithelial lesions in Makurdi, Nigeria ${ }^{a}(n=253)$

\begin{tabular}{|c|c|c|c|}
\hline Characteristic & $\operatorname{SIL}(n=45)^{b}$ & No SIL $(n=208)^{c}$ & $P$ value \\
\hline Age, years & $36 \pm 7$ & $33 \pm 5$ & 0.009 \\
\hline Parity & $2 \pm 7$ & $2 \pm 3$ & 0.34 \\
\hline Lifetime sexual partners & $5 \pm 4$ & $5 \pm 3$ & 0.84 \\
\hline $\begin{array}{l}\text { Mean duration } \\
\text { on HAART (months) }\end{array}$ & $17 \pm 6$ & $15 \pm 6$ & 0.32 \\
\hline Tobacco smoking, $\%$ & 9.3 & 7.1 & 0.47 \\
\hline $\begin{array}{l}\text { Previous sexually } \\
\text { transmitted infection, \% }\end{array}$ & 41.7 & 36.5 & 0.43 \\
\hline $\begin{array}{l}\text { Median CD4 count, } \\
\text { cell } / \mathrm{mm}^{3}\end{array}$ & 132 & 184 & 0.03 \\
\hline $\begin{array}{l}\text { Median HIV-I RNA, } \\
\text { copies/mL }\end{array}$ & 102,705 & 64,391 & 0.002 \\
\hline
\end{tabular}

Notes: ${ }^{a}$ Values are given as the mean \pm standard deviation, percentage, or median, unless otherwise indicated; bSIL group consists of those with low-grade squamous intraepithelial lesions $(n=16)$ and high-grade squamous intraepithelial lesions $(n=29) ;$ ' no SIL group consists of those with normal smears $(n=107)$ and those with atypical squamous cells of undetermined significance $(n=\mid 0 I)$.

Abbreviations: HAART, highly active antiretroviral therapy; SIL, squamous intraepithelial lesions; HIV-I, human immunodeficiency virus type I.

of all types of SIL was significantly associated with a CD4 count $<200$ cells $/ \mathrm{mm}^{3}$ and HIV-1 RNA viral load $>10,000$ copies/mL. Low CD4 count $<200$ cells $/ \mathrm{mm}^{3}$ and HIV-1 RNA viral load $>10,000$ copies/mL remained significantly associated with SIL when the variables were analyzed for risk of either low-grade SIL alone or high-grade SIL alone.

\section{Discussion}

During the early days of the HIV epidemic, HIV-infected women who had cervical human papillomavirus infection and SIL frequently died of AIDS well before developing invasive cervical cancer. However, following the introduction of HAART, the clinical course of HIV has been substantially prolonged, making HIV-infected women a clinically significant group of patients who have an increased risk of acquiring human papillomavirus infection and developing SIL and invasive cervical cancer. ${ }^{15}$ This study provides the first comprehensive analysis of the prevalence of cervical SIL, the precursor to invasive cervical cancer, in this population in Makurdi, Nigeria.
The prevalence of SIL among the HIV-1 infected women in this study was $17.8 \%$. Anorlu et $\mathrm{al}^{6}$ recently reported a lower prevalence of $10.9 \%$ in HIV-positive women in Lagos, Nigeria. The reported prevalence in this study is also higher than the $2.9 \%$ and $13.3 \%$, respectively, reported by Kapiga et $\mathrm{al}^{16}$ among HIV-seropositive pregnant women in Tanzania and Chalermchockcharoenkit et $\mathrm{al}^{17}$ among HIV-infected women by postpartum Papanicolaou smear in Thailand. The fact that the other studies were conducted among pregnant and postpartum women may have contributed to the observed variation. However, other researchers have reported higher prevalences in Africa involving HIV-positive women in Jos, Nigeria (29\%), ${ }^{14}$ commercial sex workers in Kenya (26\%), ${ }^{18}$ and sexually transmitted disease clinic attendees in Zambia (56\%). ${ }^{19}$ The difference between the findings of this study and those of other researchers may be attributed to the different populations sampled and possibly the different stages of HIV infection. Elsewhere, Lehtovirta et $\mathrm{al}^{20}$ found a prevalence of $33 \%$ in a cohort of HIV-infected women in Helsinki, Finland. The prevalence of SIL in the general Nigerian population ranges from $4.1 \%$ to $11.8 \%{ }^{14}$ These rates in the general population are less than the $17.8 \%$ reported in this study.

Previous studies have not satisfactorily established a protective effect of antiretroviral treatment on the risk of SIL. HAART showed some potential effect in the Women's Interagency HIV study. ${ }^{21}$ Heard et al ${ }^{22}$ showed that HAART had a positive impact on regression of SIL, and this was associated with increasing CD4 cell counts. In other studies, the effect of HAART on the prevalence of SIL has not been significant ${ }^{14,20}$ or the prevalence of SIL has remained unchanged. ${ }^{23}$ Similarly in this study, the use of HAART was not associated with a significant reduction in the risk of SIL.

Immunosuppression by HIV infection is a strong risk factor for SIL. In this study, $49.4 \%$ of HIV-positive women had CD4 counts $<200$ cells $/ \mathrm{mm}^{3}$, which is diagnostic of immunologic AIDS. In a recent review in Jos, Nigeria, Agaba et $\mathrm{al}^{14}$ found that $60.9 \%$ of their $369 \mathrm{HIV}$-positive women had CD4 counts $<200$ cells $/ \mathrm{mm}^{3}$. The lower percentage of women

Table 3 Multivariate analysis of risk factors for cervical SIL among HIV-I infected women in Makurdi, Nigeria

\begin{tabular}{|c|c|c|c|c|c|c|c|c|c|}
\hline & \multicolumn{3}{|c|}{ Variable all SIL } & \multicolumn{3}{|c|}{ Low-grade SIL } & \multicolumn{3}{|c|}{ High-grade SIL } \\
\hline & AOR 95\% & Cl & $P$ value & AOR 95\% & $\mathrm{Cl}$ & $P$ value & AOR 95\% & $\mathrm{Cl}$ & $P$ value \\
\hline Age $>35$ years & 1.29 & $0.68-2.34$ & 0.35 & 1.29 & $0.68-2.34$ & 0.35 & 1.02 & $0.63-2.17$ & 0.79 \\
\hline CD 4 count $<200$ cells $/ \mathrm{mm}^{3}$ & 3.64 & $1.40-5.17$ & 0.04 & 3.63 & $1.39-5.16$ & 0.05 & 4.95 & $2.16-7.83$ & 0.002 \\
\hline HIV-I RNA > 10000 copies $/ \mathrm{mL}$ & 2.58 & $1.08-3.87$ & 0.03 & 2.58 & $1.08-3.87$ & 0.03 & 3.67 & $1.73-6.39$ & $<0.001$ \\
\hline
\end{tabular}

Abbreviations: AOR, adjusted odds ratio; Cl, confidence interval; HIV-I, human immunodeficiency virus type I; SIL, squamous intraepithelial lesions. 
with immunologic AIDS in this study may partly explain the lower prevalence of SIL of $17.8 \%$ in this study as compared with $29 \%$ in the Jos study. This study also showed that the CD4 count was inversely associated with SIL, and women with a CD4 count $<200$ cells $/ \mathrm{mm}^{3}$ were at greater risk of SIL compared with women with CD4 counts $>200$ cells $/ \mathrm{mm}^{3}$. This finding is in accordance with several other studies involving HIV-positive women. ${ }^{8,14,16,17,20,24}$ Davis et al ${ }^{13}$ reported that the strongest predictor of genital dysplasia was a nadir CD4 and CD4 count $<200$ cells $/ \mathrm{mm}^{3}$. Prolonged CD4 lymphopenia in patients infected with HIV results in defective T-cell proliferation regardless of the current CD4 count or viral load. ${ }^{14}$ The CD4 count was independent of HAART use and HIV-1 RNA viral load as a risk factor for SIL in this study.

HIV-1 RNA levels have been directly correlated with a higher risk of SIL. ${ }^{25}$ In this study, the median HIV-1 RNA viral load was significantly higher in patients with SIL than in those without SIL. Furthermore, an HIV-1 RNA viral load $>10,000$ copies $/ \mathrm{mL}$ was associated with SIL in multivariate analysis. However, a high level of HIV/RNA does not always predict the risk of SIL, because some studies have failed to show a positive association. ${ }^{13}$ For instance, Agaba et $\mathrm{al}^{14}$ observed that although the HIV viral load was higher in patients with SIL, it was not predictive of SIL in multivariate analysis.

This study is not without important limitations. First, it was essentially a cross-sectional study, with a Papanicolaou smear taken only once at recruitment. Follow-up with multiple Papanicolaou smears over a period of time would have been ideal. Another limitation was the fact that SIL was determined using only cytology without histologic confirmation. There was also no end-of-study colposcopy to seek occult lesions. This leaves the possibility of underestimation of the endpoints of low-grade SIL and high-grade SIL.

In conclusion, a high prevalence of cervical SIL was found among HIV-1 infected women in Makurdi, Nigeria. Decreased CD4 cell counts and increasing HIV-1 RNA viral load were associated with cervical SIL. CD4 cell counts $<200$ cells $/ \mathrm{mm}^{3}$ and HIV-1 RNA viral loads $>10,000$ copies $/ \mathrm{mL}$ were significantly associated with cervical SIL. Accordingly, HIV treatment programs and clinics must as a matter of policy institute comprehensive reproductive health care services for this high-risk group, including routine Papanicolaou smear screening.

\section{Disclosure}

The authors report no conflicts of interest in this work.

\section{References}

1. Ferlay J, Bray F, Pisani P, Parkin DM. GLOBOCAN 2002 Cancer Incidence. Mortality and Prevalence Worldwide. IARC Cancer Base No. 5 version 2.0. Lyon, France: IARC Press; 2004.

2. Parkin DM, Pisani P, Ferlay J. Estimates of the worldwide incidence of 25 major cancers in 1990. Int J Cancer. 1999;80:827-841.

3. World Health Organization. Comprehensive Cervical Cancer Control. A Guide to Essential Practice. Geneva, Switzerland: World Health Organization; 2006.

4. Parkin DM, Bray F. The burden of HPV-related cancers. Vaccine. 2006;24:S3/11-24.

5. Stjernsward J, Eddy D, Luthra U, Stanley K. Plotting a new course for cervical cancer screening in developing countries. World Health Forum. $1987 ; 8: 42-45$.

6. Anorlu RI, Igwilo CI, Akanmu AS, et al. Prevalence of abnormal cervical smears among patients with HIV in Lagos, Nigeria. West Afr J Med. 2007;26:143-147.

7. El-Ghobashy A, Herrington S. Cervical cancer: epidemiology and molecular characterization. In: Studd J, editor. Progress in Obstetrics and Gynaecology. Vol 16. London, UK: Elsevier Science Limited; 2005.

8. Centers for Disease Control and Prevention. 1993 revised classification system for HIV infection and expanded surveillance case definition for AIDS among adolescents and adults. MMWR Morb Mortal Wkly Rep. 1992;4(RR-17)1:1-19.

9. Adewole IF, Odutolu O, Sagay AS. Prevention of mother to child transmission of HIV. In: Adeyi O, Kanki PJ, Odutolu O, Idoko J, editors. AIDS in Nigeria: A Nation on the Threshold. Cambridge, MA: Harvard Centre for Population and Development Studies; 2006.

10. Federal Ministry of Health. National Guidelines on Prevention of Mother To Child Transmission of HIV in Nigeria. Abuja, Nigeria: Federal Ministry of Health; 2007.

11. National Agency for the Control of AIDS. National Policy on HIV AIDS. Abuja, Nigeria: National Agency for the Control of AIDS; 2009.

12. Joint United Nations Programme on HIV/AIDS. AIDS Epidemic Update. Geneva, Switzerland: Joint United Nations Programme on HIV/AIDS; 2004.

13. Davis AT, Chakraborty H, Flowers L, Mosunjac MB. Cervical dysplasia in women infected with HIV: a correlation with HIV viral load and CD4 count. Gynaecol Oncol. 2001;80:350-354.

14. Agaba PA, Thacher TD, Ekwempu CC, Idoko JA. Cervical dysplasia in Nigerian women infected with HIV. Int J Gynecol Obstet. 2009;107:99-102.

15. Branca M, Garbuglia AR, Benedetto A, et al. Factors predicting the persistence of genital human papillomavirus infections and Pap smear abnormality in HIV-positive and HIV-negative women during prospective follow-up. Int J STD AIDS. 2003;14:417-425.

16. Kapiga SH, Msamanga GI, Spiegelman D, Mwakyoma H, Fawzi WW, Hunter DJ. Risk factors for cervical squamous intraepithelial lesions among HIV-1 seropositive women in Dar es Salaam, Tanzania. Int $J$ Gynecol Obstet. 1999;67:87-94.

17. Chalermchockcharoenkit A, Srimai K, Chaisilwattana P. High prevalence of cervical squamous cell abnormalities among HIV-infected women with immunological AIDS-defining illnesses. J Obstet Gynaecol Res. 2006;32:324-329.

18. Kreiss JK, Kiviat NB, Plummer FA, et al. Human immunodeficiency virus, human papillomavirus, and cervical intraepithelial neoplasia in Nairobi prostitutes. Sex Transm Dis. 1992;19: 54-59.

19. Parham GP, Sahasrabuddhe VV, Mwanahamuntu MH, et al. Prevalence and predictors of squamous intraepithelial lesions of the cervix in HIV-infected women in Lusaka, Zambia. Gynecol Oncol. 2006;103:1017-1022.

20. Lehtovirta P, Paavonen J, Heikinheimo O. Risk factors, diagnosis and prognosis of cervical intraepithelial neoplasia among HIV-infected women. Int J STD AIDS. 2008;19:37-41. 
21. Minkoff H, Ahdieh L, Massad LS, et al. The effect of highly active antiretroviral therapy on cervical cytologic changes associated with oncogenic HPV among HIV-infected women. AIDS. 2001;15: 2157-2164.

22. Heard I, Tassie JM, Kazatchkine M, Orth G. Highly active antiretroviral therapy enhances regression of cervical intraepithelial neoplasia in HIV-seropositive women. AIDS. 2002;16:1799-1802.

23. Moore AL, Sabin CA, Madge S, et al. Highly active antiretroviral therapy and cervical intraepithelial neoplasia. AIDS. 2002;16:927-929.
24. Mangclaviraj S, Kerr SJ, Chaithongwongwatthana S, et al. Nadir CD4 count and monthly income predict cervical squamous cell abnormalities in HIV-positive women in a resource-limited setting. Int J STD AIDS. 2008;19:529-532.

25. Luque AE, Demeter LM, Reichman RC. Association of human papillomavirus infection and disease with magnitude of human immunodeficiency virus type-1 (HIV-1) RNA plasma level among women with HIV-1 infection. J Infect Dis. 1999;179:1405-1409.

\section{Publish your work in this journal}

The International Journal of Women's Health is an international, peerreviewed open-access journal publishing original research, reports, reviews and commentaries on all aspects of women's healthcare including gynecology, obstetrics, and breast cancer. Subject areas include: Chronic conditions (migraine headaches, arthritis, osteoporosis);
Endocrine and autoimmune syndromes; Sexual and reproductive health; Psychological and psychosocial conditions. The manuscript management system is completely online and includes a very quick and fair peer-review system. Visit http://www.dovepress.com/ testimonials.php to read real quotes from published authors. 